\title{
LA POLIITICA DE PRIVACIÓN DEL SUFRAGIO A LOS PRESOS: ¿UNA AMENAZA PARA LA DEMOCRACIA?*
}

\author{
Mandeep K. Dhami**
}

\begin{abstract}
RESUMEN
El derecho de voto es uno de los principios fundamentales de la democracia. Sin embargo, el sufragio universal de la población adulta no se ha visto realizado en muchas de las democracias actuales. Internacionalmente, millones de presos (y ex delincuentes, en algunos países) han sido privados del sufragio. La exclusión del proceso cívico es una amenaza a la democracia. En este artículo sostengo que eliminar el derecho a votar de un preso puede conducir a la desigualdad y la injusticia que es contraria a los ideales democráticos. Por el contrario, la restitución del sufragio de los presos puede favorecer su rehabilitación y reinserción social, y puede tener un impacto real sobre el clima político de un país. También discuto los argumentos a favor y en contra de la privación del derecho a sufragio a los presos, exploro la opinión pública sobre esta cuestión y realizo un seguimiento de los últimos cambios legislativos a la política de privación del sufragio internacionalmente. Son destacadas áreas para la futura investigación psicológica.
\end{abstract}

PRIVACIÓN DEL SUFRAGIO - DEMOCRACIA - PRESOS

Prisoner disenfranchisement policy: a threat to democracy?

\begin{abstract}
The right to vote is one of the fundamental principles of democracy. However, full suffrage of the adult population has not been realized in many present-day democracies. Internationally, millions of prisoners (and ex-offenders in some nations) are disenfranchised. Being excluded from the civic process is a threat to democracy. In this article, I argue that removing a prisoner's right to vote can lead to inequality and injustice that is counter to democratic ideals. By contrast, enfranchisement of prisoners can promote their rehabilitation and social reintegration, and can have a real impact on the political climate of a nation. I also discuss the arguments for and against prisoner disenfranchisement, explore public opinion on this issue, and track recent legislative changes to disenfranchisement policy internationally. A reas for future psychological inquiry are highlighted.
\end{abstract}

\section{DISENFRANCHISEMENT - DEMOCRACY - PRISONERS}

* Este trabajo fue publicado en su idioma original en Analyses of Social Issues and Public Policy, Vol. 5, $\mathrm{N}^{\circ} 1$, 2005. Su traducción al español corresponde a Pablo Marshall Barberán, profesor de Derecho Constitucional de la Universidad Austral de Chile.

** Doctora en Derecho, Profesora de Criminología en el Instituto de Criminología de la Universidad de Cambridge. Su investigación se concentra en los ámbitos de toma de decisiones jurídicas, la psicología del encarcelamiento y la justicia restaurativa.

Artículo recibido el 31 de julio de 2009 y aceptado para su publicación por el Comité Editorial el 26 de octubre de 2009. 
$\mathrm{L}$ os principios básicos de la democracia electoral son establecidos en el derecho internacional. El artículo 25 del Pacto Internacional de Derechos Civiles y Políticos (PIDCP) declara que "Todos los ciudadanos gozarán, sin ninguna de las distinciones mencionadas en el artículo 2, y sin restricciones indebidas, de los siguientes derechos y oportunidades: [...] (b) Votar y ser elegidos en elecciones periódicas, auténticas, realizadas por sufragio universal e igual y por voto secreto que garantice la libre expresión de la voluntad de los electores"; el artículo 2, establece que esto se aplica "sin distinción alguna de raza, color, sexo, idioma, religión, opinión política o de otra índole, origen nacional o social, posición económica, nacimiento o cualquier otra condición social". Aunque el derecho internacional no siempre forma parte del derecho interno de los países, él tiende a influir en la legislación nacional y ser utilizado como referencia para evaluar esa legislación.

Cientistas políticos tales como Robert A. Dahl también sostienen que el proceso democrático debe permitir que todos los miembros adultos de un estado tengan una igual y efectiva oportunidad de contribuir a la agenda política y votar sobre ella, de manera que cada voto cuente por igual. ${ }^{1}$ Históricamente, no hubo sufragio universal de la población adulta. ${ }^{2}$ Por ejemplo, en muchos países a las mujeres, a los pobres, a los negros y a los pueblos indígenas se les negó el derecho a voto. Hasta la fecha, un segmento de la población adulta, es decir, los presos (probationers, farolees y los ex delincuentes en algunos países), ${ }^{3}$ son marginados en muchas democracias. El que sean excluidos del proceso cívico es una amenaza para la democracia. En este artículo voy a argumentar que la eliminación del derecho a votar de los presos puede tener ramificaciones negativas para los ideales democráticos de igualdad y justicia. Por el contrario, incluir a los presos (probationers, parolees y ex delincuentes) puede promover su rehabilitación y reinserción social, y puede tener un impacto real sobre el clima político de un país. En primer lugar, sin embargo, voy a comenzar con una breve revisión de la política comparada de privación, seguido de un examen de las justificaciones a favor y en contra de negar el derecho de voto a los presos y de la opinión pública sobre esta cuestión. Hay una escasez de investigación psicológica sobre la privación del sufragio de los presos. De esta manera, voy a destacar áreas para futura investigación psicológica.

${ }^{1}$ Dahl, R., A preface to democratic theory. University of Chicago Press, Chicago, 1956; y Dahl, R., On democracy. Yale University Press, New Haven, 1998.

${ }^{2}$ N. del T.: "Full suffrage" en el original.

${ }^{3} \mathrm{~N}$. del T.: Las expresiones probationers y parolees no han sido traducidas. Ellas equivalen a formas de libertad condicional. La probation es una decisión judicial en la que el condenado goza de libertad bajo la supervisión del probarion officer durante un período no superior a 3 años. En la parole un preso condenado obtiene el beneficio administrativo de la libertad bajo palabra, una vez que ha cumplido parte de su condena efectivamente. 


\section{LOS PRESOS Y EL DERECHO AL VOTO}

Internacionalmente, las políticas en materia de derechos de voto de los presos transitan a lo largo de un abanico de alternativas. ${ }^{4}$ Por un lado, hay países que permiten a los presos votar (por ejemplo, Canadá, Ucrania, Sudáfrica e Irán). Por otro, hay países que prohíben votar a los presos, y esta política de privación varía. Varios países restringen la votación a determinados grupos de presos. Por ejemplo, en Australia los condenados a más de 5 años no pueden votar, mientras que en China es para los condenados a muerte que está prohibidos votar. Muchos países tienen una prohibición más o menos indiscriminada respecto del voto de los presos (por ejemplo, el Reino Unido y Rusia). Por último, hay unos pocos países, tales como Finlandia, que prohíben votar a los presos por algún tiempo después de finalizado su encarcelamiento. Algunos estados en los Estados Unidos tienen una de las más restrictivas políticas en este sentido; privan del derecho a voto permanentemente a los criminales. ${ }^{5}$

Aunque la mayoría de las políticas de privación del voto se refieren a los presos condenados, los presos en espera de juicio o de condena son a menudo "prácticamente" privados del voto, con poca oportunidad de votar en la cárcel. Se estima que casi 4,5 millones de personas, en 54 países, han sido privados de su derecho al voto debido a la encarcelación. ${ }^{6}$ Esta es una estimación conservadora, ya que excluye a las países que sólo restringen el voto de determinados grupos de presos. En lo que sigue, ofrezco una visión general de la política de privación del voto a criminales en los Estados Unidos tomando en consideración que tiene algunas de las más restrictivas políticas a nivel estatal entre los países democráticos. Asimismo, discuto algunas de las recientes reformas de los derechos a voto de los presos en el Canadá y el Reino Unido.

\section{Estados Unidos: una democracia que priva del sufragio}

Es la legislación de cada Estado la que determina si una persona con una condena por un crimen tiene derecho a votar, tanto en elecciones estatales como en elecciones federales. ${ }^{7}$ Actualmente, 16 estados niegan el voto a criminales encarcelados, pero conceden el voto a aquellos que están fuera de la cárcel bajo probation o parole; 4 estados sólo permiten a los criminales bajo probation votar y privan del voto tanto a parolees como a quienes están en la cárcel; 31 estados privan del voto a todos los criminales bajo

${ }^{4}$ Véase Rottinghaus, B., Manatt, C., Manatt, K., Incarceration and enfranchisement: International practices, impact, and recommendations for reform. International Foundation for Election Systems, Washington, 2003.

5 Voy a utilizar el término "criminal" [felon] al referirme a los Estados Unidos, ya que las leyes de privación se refieren a los culpables de una felony (delito grave), y voy a utilizar el término "preso" [prisoner] al referirme a otros países, porque las leyes de privación se refieren típicamente a las personas condenadas a penas de prisión.

${ }^{6}$ Rottinghaus et al., op. cit. en nota 4.

${ }^{7}$ Véase Keyssar, A., The right to vote: A contested history of democracy in the United States. Basic Books, New York, 2000. 
probation, en la cárcel y bajo parole y, finalmente, 14 estados eliminan de manera efectiva el derecho a votar de todos los condenados por delitos graves, incluidos quienes ya han cumplido su condena ( 5 estados privan en forma permanente a ex criminales, mientras que en los otros 9 estados los ex criminales pueden recuperar el derecho después de un período de tiempo). ${ }^{8}$ Los crímenes por los que las personas son privados de su derecho a voto pueden incluir hurto, la posesión de una pequeña cantidad de marihuana y los delitos de cuello blanco. Incluso en estados donde los criminales recuperan el derecho a voto a la salida de la cárcel o tras la finalización de su condena, (ex) criminales pueden no estar conscientes de esta política. Además, en algunos estados donde los ex criminales puedan recuperar el derecho a voto después de un período de tiempo, éstos deben emprender un largo y arduo procedimiento. Se estima que alrededor de 4 millones de estadounidenses están privados del derecho a votar, y más de 1 millón de esas personas ya han cumplido su condena. ${ }^{9}$

En 1974 la Corte Suprema de los Estados Unidos confirmó el derecho de los estados a prohibir que los criminales votaran en Richardson v. Ramírez. Las leyes estatales de privación han cambiado con el tiempo. ${ }^{10}$ En algunos casos, estos cambios han sido restrictivos. Por ejemplo, recientemente se aprobó la legislación de Massachusetts que eliminó el derecho de voto de los criminales encarcelados que anteriormente tenían ese derecho, y Kansas ahora también prohíbe la votación de criminales bajo probation. Sin embargo, también hay un creciente movimiento de reforma que tiene por objeto restablecer el derecho de voto o expandirlo. Por ejemplo, Connecticut ahora permite votar a criminales bajo probation, Nebraska ha sustituido la prohibición de votar de porvida con una prohibición de 2 años después de cumplida la condena, y Nuevo México ahora ha restaurado el derecho de voto a los criminales tras la finalización de su condena.

\section{La reforma democrática: liberar el voto}

Canadá. En octubre de 2002 la Corte Suprema de Canadá, en Sauvé v. Canada, rechazó la legislación federal que prohibía a los presos votar por una mayoría de 5 a 4 . El Gobierno había afirmado que la privación del voto estaba justificada en el argumento de que aumentaría la responsabilidad cívica y el respeto del imperio de la ley, ${ }^{11}$ y que proporcionaría un castigo adicional. La visión de la mayoría, resumida por el Juez McLachlin, fue la siguiente:

${ }^{8}$ The Sentencing Project, Felony disenfranchisement laws in the United States. Retrieved April 23, 2005 from http://www.sentencingproject.org/pdfs/1046.pdf

${ }^{9}$ Fellnar, J., Mauer, M., Losing the vote. The impact of felony disenfranchisement laws in the United States. Human Rights Watch and The Sentencing Project, New York, 1998.

${ }^{10}$ Véase Allard, P., Mauer, M., Regaining the vote: An assessment of activity relating to felon disenfranchisement laws. Sentencing Project, New York, 2000; Uggen, C., Retrieved December 13, 2004, from http:// www.righttovote.org/upload/resources/167_UFile_UggenManzaSummary.pdf

${ }^{11}$ N. del T.: Rule of law en el original. 
La legitimidad de la ley y la obligación de obedecer la ley se derivan directamente del derecho de todo ciudadano a votar. Denegar a los reclusos el derecho a votar es perder un medio importante de enseñarles los valores democráticos y la responsabilidad social [...] La negación del derecho de voto sobre la base de atribuir indignidad moral es incompatible con el respeto de la dignidad de cada persona [...] También es contrario a la idea [...] de que las leyes exigen obediencia, ya que son hechas por aquellos cuya conducta rigen. Negar el derecho de voto no cumple con los requisitos de un castigo legítimo, a saber, que el castigo no debe ser arbitrario y debe servir a un propósito válido para el derecho penal [...] En cuanto a un propósito penal legítimo, ni el reporte ni el sentido común apoyan la afirmación de que la privación disuade a los criminales de delito o los rehabilita.

Por supuesto, el reciente cambio en la política no significa que la privación del voto no será nuevamente reintroducida. En el futuro, los presos de Canadá que cumplen condenas por delitos específicos podrán ser privados del derecho a voto. Además, los jueces pueden dar poderes para eliminar el derecho a votar como parte de una pena judicial. Sin embargo, por ahora, los presos de Canadá tienen derecho a voto. Aproximadamente un tercio estaba registrado para votar en las elecciones federales de 2004, aunque se desconoce cuántos ejercieron este derecho. ${ }^{12}$

Reino Unido. La sentencia de la Corte Europea de Derechos Humanos en Hirst v. United Kingdom, en marzo de 2004, puso en tela de juicio la validez de la prohibición sobre el derecho de voto de los presos. El Gobierno había afirmado que la privación se dirigía a prevenir el delito y castigar a los delincuentes, y mejorar la responsabilidad cívica y el respeto del imperio de la ley. Se argumentó que los presos condenados habían incumplido el contrato social y así perdido el derecho a participar en el proceso cívico durante la duración de su condena. El Tribunal siguió el razonamiento de la mayoría en el caso Sauvé v. Canada. Además, el tribunal declaró que

[E] 1 hecho de que un recluso condenado esté privado de su libertad no significa que pierde la protección de otros derechos fundamentales [...], a pesar de que el disfrute de esos derechos deben inevitablemente ser atemperada por las exigencias de su situación [...] No hay una clara y lógica relación entre la pérdida del voto y la imposición de una pena de prisión, where no bar applies to a persona culpable de delitos que pueden ser igualmente antisociales o 'anticiudadanos', ${ }^{13}$ pero cuyo crimen no se encontró con tal consecuencia.

${ }^{12}$ Sheppard, M. (Executive Producer). Canadian prisoners exercise right to vote (2004, June 18). News of CBC. Toronto: Canadian Broadcasting Corporation.

${ }^{13}$ N. del T.: 'uncitizen-like' en el original. 
Una vez más, sin embargo, la corte dejó abierta la posibilidad de eliminar el voto de los presos condenados por determinado tipos de delitos, o para permitir a los jueces prohibir votar a los presos como parte de su condena. El Gobierno del Reino Unido se encuentra actualmente disputando esta sentencia, y Juliet Lyon, directora de la Prison Reform Trust, afirma que está "preocupada de que el gobierno esté usando este prolongado proceso como forma de asegurarse de que no tendrá que lidiar con la rehabilitación del derecho a voto de los presos en las próximas elecciones generales" (comunicación personal, 18 de enero de 2005). De hecho, los presos en el Reino Unido no pudieron votar el 5 de mayo de 2005.

\section{PRIVACIÓN DEL DERECHO A VOTO: JUSTIFICACIONES Y OPINIÓN PÚBLICA}

\section{¿Deben los reclusos enfrentar una muerte cívica?}

Las leyes de privación del voto reflejan el concepto de "muerte civil" o de retirada de la vida política y jurídica y del ejercicio de los derechos civiles, todas ellas originarias de la antiguas sociedades griega y romana y adoptadas por la Europa medieval. ${ }^{14}$ Filósofos como John Locke, Jean-Jacques Rousseau, Immanuel Kant y John Stuart Mill han apoyado la legitimidad de la privación del voto. ${ }^{15}$ Los casos judiciales antes expuestos ilustran argumentos a favor y en contra de la privación del voto en las sociedades democráticas contemporáneas. ${ }^{16}$ Para reiterar, entre las razones comúnmente invocadas para descalificar a los presos de la votación se incluyen, que ello promueve la responsabilidad cívica y el respeto de la ley; que los delincuentes han perdido el derecho de voto desde que violaron el "contrato social"; que éste es un método de control de la criminalidad; que la "pureza de las urnas" debe ser protegida de los delincuentes que podrían corromperla, actuar subversivamente o cometer fraude electoral, y que es costoso y poco práctico permitir a los presos votar. A menudo, la privación del voto a los presos es considerada simplemente como otra restricción a la libertad de las personas que están encarceladas.

Sin embargo, el argumento de que permitir que los presos voten sería costoso y poco práctico es éticamente injustificable. Del mismo modo, el hecho de que los presos pierden muchas libertades no implica que deban perder todos sus derechos civiles. Negar a los presos el derecho a voto posiblemente socava el respeto al imperio de la ley desde que los ciudadanos que no pueden participar en la elaboración de las leyes probablemente no reconocerán su autoridad. Permitir que los presos voten, por el contrario,

${ }^{14}$ Véase Ewald, A., “Civil death”": The ideological paradox of criminal disenfranchisement laws in the United States". Wisconsin Law Review, 5, 2002, pp. 1045-1138; Itkowitz, H., Oldak, L., "Restoring the ex-offender's right to vote: Background and developments". American Criminal Law Review, 11, 1973, pp. 721-770; Keyssar, op. cit. en nota.

${ }^{15}$ Ver Planinc, Z., "Should imprisoned criminals have a constitutional right to vote?". Canadian Journal of Law and Society, 2, 1987, pp. 153-164.

${ }^{16}$ Véase también Itkowitz y Oldak, op. cit. en nota 14. 
puede reforzar sus vínculos sociales y su compromiso con el bien común, por lo tanto, promover la participación lícita y responsable en la sociedad civil. Sugerir que los presos han perdido el derecho a votar porque han violado el contrato social implica que ellos escogieron deliberada y racionalmente la actividad criminal con el conocimiento de que pueden perder sus derechos de voto. En muchos casos, las causas de la criminalidad van más allá de la elección individual y los delincuentes suelen ser ignorantes de las políticas de privación del derecho a voto.

Como método de lucha contra la criminalidad o como objetivo del sistema penal, la privación del voto es retributiva en la medida en que el delincuente sea privado de algo que él o ella valore. La privación puede no ser retributiva, si los delincuentes ya se sienten alienados de la vida civil y política, y no enmienda el daño ya causado. Tampoco hay pruebas para demostrar que la privación del voto rehabilita, incapacita o disuade a los delincuentes. La privación del voto socava el objetivo rehabilitador de desarrollar la personalidad de los delincuentes y reinsertarlos a la sociedad en cuanto ella puede reducir la autoestima de los delincuentes y alienarlos de la comunidad. De hecho, como se señalará más adelante, la privación del voto puede fomentar aún más el comportamiento criminal. La disuasión a través de la privación del voto es difícil de lograr porque las personas rara vez son conscientes de esta consecuencia, y es poco probable que encuentren en ello un factor de disuasión suficiente (sobre todo cuando no son disuadidos por largas penas de cárcel). En efecto, los Estados o países con discapacidades civiles resultantes de una condena, por ejemplo, la reducción de los derechos de orden familiar (por ejemplo, la terminación de la patria potestad y los motivos legales para el divorcio) y la reducción de derechos que involucran confianza y seguridad (por ejemplo, la privación del derecho a servir como jurado y a poseer un arma de fuego) no necesariamente tienen un menor índice de criminalidad. Por último, el uso de la privación del voto como una incapacidad no es plausible para los delincuentes que no son culpables de delitos relacionados con las elecciones.

La idea de que la pureza de las urnas debe ser preservada destaca tres preocupaciones. La primera preocupación es que los delincuentes "corromperían”, "mancharían” o "infectarían” la sociedad, es vaga y mal definida. ¿Permitiendo que los delincuentes voten realmente se pone en peligro la sociedad civil? La segunda preocupación es que los delincuentes pueden votar subversivamente en las urnas. Para ello sería necesario que los candidatos presentaran políticas rebeldes, y un número suficiente de delincuentes organizados. Tampoco hay pruebas de que los delincuentes tienen más probabilidades que otros grupos de votar en una forma subversiva o rebelde. De hecho, Casper encontró que los criminalmente acusados creían que la ley es digna de respeto. ${ }^{17}$ Al igual que otras personas, los delincuentes tenderán a emitir su voto basado en algo más que el propio interés o un tema en particular. De todos modos, excluir a un grupo sobre la base de cómo vota es antidemocrático. La tercera preocupación es que los delincuentes puedan cometer fraude electoral. Sin embargo, no hay relación entre la comisión de 
delitos electorales y otros tipos de delitos. Además, una persona que cometió un delito electoral en el pasado no necesariamente cometerá un crimen similar en el futuro.

El desempoderamiento político de un segmento de la sociedad pone en peligro la legitimidad de una democracia. La futura investigación psicológica podría explorar los motivos que justifican las políticas de privación del voto a los presos. Por ejemplo, ¿en qué medida el acto de votar afecta los sentimientos de pertenencia a una comunidad más amplia? ¿Las personas perciben la votación como un comportamiento egoísta o altruista? ¿Las personas creen que la eliminación del derecho de voto actuará como una disuasión suficiente para los criminales? ¿Qué se le atribuye a las personas que están privadas del derecho a voto? ¿Cuáles son las similitudes y diferencias entre la visión de la víctimas y la de los delincuentes acerca de la privación del voto? ¿Cómo el patrón de voto de los presos difiere del comportamiento del electorado en general?

\section{¿Es la privación del voto una sentencia pública?}

Hasta la fecha, ciertos investigadores han estudiado la opinión pública estadounidense acerca de la política de privación del voto a los presos. En un estudio nacional de 503 personas, Pinaire, Heumann y Bilotta encontraron que más del $90 \%$ cree que el derecho al voto es uno de los (o el) más importante(s) derecho(s) en una democracia. ${ }^{18}$ Sólo una minoría de los encuestados apoya uno de los dos extremos de las políticas criminales de privación del voto: el $10 \%$ no cree en ninguna prohibición a la votación de los criminales, y el $16 \%$ cree en una prohibición permanente para todas las personas condenadas por un delito grave. La mayoría de la población, por lo tanto, adoptó una posición moderada: $32 \%$ cree que sólo los criminales encarcelados deberían perder su derecho a voto, y el $35 \%$ cree que los criminales deberían perder su derecho a voto sólo mientras están en prisión, bajo probation, o bajo parole. En otro estudio nacional de 1.000 personas, Manza, Brooks y Uggen encontraron que el nivel de apoyo a la inclusión disminuye en función del status del delincuente: ex criminal (80\%), probationer (68\%), parolee (60\%) y preso (31\%). ${ }^{19}$ Así pues, aunque la opinión pública de los EE.UU. respalda el derecho al voto de los ex delincuentes, continúa a favor de la eliminación del voto a los presos. Es probable que la opinión pública en otros países con menos políticas de justicia punitiva estarían a favor de la inclusión de los presos, lo que apoya los principios de la democracia y el respeto de las libertades civiles.

Un hallazgo interesante que emerge del estudio de Manza Brooks y Uggen es que el apoyo público a la inclusión se asoció con el tipo de delito. ${ }^{20}$ En concreto, hubo menos apoyo a la inclusión de los delincuentes sexuales. La investigación psicológica podría examinar los factores subyacentes a esta actitud punitiva más intensa hacia los

${ }^{18}$ Pinaire, B., Heumann, M., Bilotta, L., "Barred from the vote: Public attitudes toward the disenfranchisement of felons". Fordham Urban Law Journal, 30, 2003, pp. 1519-1550.

${ }^{19}$ Manza, J., Brooks, C., Uggen, C., "Public attitudes toward felon disenfranchisement in the United States”. Public Opinion Quarterly, 68, 2004, pp. 275-286.

${ }^{20}$ Ibid. 
delincuentes sexuales. ¿Es principalmente influenciada por el deseo de retribución? Además, ¿cuáles son los factores que influyen en un mayor apoyo público a la inclusión de los ex criminales frente a los presos? La investigación podría también determinar otras situaciones límites que afectan la opinión pública sobre la política de privación del voto de los presos, así como las técnicas que podrían cambiar las actitudes hacia tal privación.

\section{LOS COSTOS DE LA PRIVACIÓN}

\section{La desigualdad}

Las leyes de privación del sufragio pueden llevar a la desigualdad. Teniendo a los Estados Unidos como un ejemplo, es evidente que hay una tasa desproporcionada de condena y encarcelamiento de los afroamericanos. Por ejemplo, en 2003, los reclusos negros de sexo masculino representaban aproximadamente el $44 \%$ de todos los reclusos con una pena de 1 año o más, mientras que los reclusos blancos representaban el $35 \%$, y hombres negros fueron encarcelados en una tasa de 3.405 por cada 100.000 habitantes, en comparación con una tasa de 465 para los hombres blancos. ${ }^{21}$ Un patrón similar emerge para las mujeres negras. Los perfiles raciales y la "guerra contra las drogas", que discrimina sistemáticamente, pueden explicar en parte estas tasas desproporcionadas. ${ }^{22}$ Sin embargo, esto ha llevado también a la desigualdad de la privación del sufragio de estos grupos. Por ejemplo, alrededor del $13 \%$ de todos los hombres afroamericanos (1,4 millones) están privados de su derecho a sufragio. ${ }^{23}$ Comprenden el $36 \%$ del total de población de los privados de sufragio a pesar de que constituyen sólo el $6 \%$ de la población total. Está previsto que tres de cada diez de la próxima generación de hombres afroamericanos perderá el derecho a voto, ya sea de forma temporal o permanente. ${ }^{24}$ Aunque las cifras comparables para los latinos aún no se han presentado, es probable que un patrón similar emergerá para este grupo minoritario. Harvey se refiere a la erosión o al desempoderamiento de los grupos minoritarios como "dilución del voto racial". ${ }^{25}$

La práctica de la privación del sufragio, junto con los desproporcionados índices de encarcelamiento de afroamericanos es discriminatoria y frustra los esfuerzos del movimiento de derechos civiles (Harvey, 1994). De hecho, varios autores han señalado la relación entre el racismo y el desarrollo de leyes de privación del sufragio a criminales en

\footnotetext{
${ }^{21}$ Bureau of Justice Statistics. Prisoners in 2003. US Department of Justice, Office of Justice Programs, Washington, 2004.

${ }^{22}$ Harvey, A. E., "Ex-felon disenfranchisement and its influence on the black vote: The need for a second look". University of Pennsylvania Law Review, 142, 1994, pp. 1145-1189.

${ }^{23}$ Fellnar, J., Mauer, M., Losing the vote. The impact of felony disenfranchisement laws in the United States. Human Rights Watch and The Sentencing Project, New York, 1998.

${ }^{24}$ Ibid.

${ }^{25}$ Harvey, op. cit. en nota 22.
} 
los Estados Unidos. ${ }^{26}$ Preuhs encontró, después revisar varios factores, que indicadores raciales tales como el tamaño de la población minoritaria explican mejor la variación de la política de privación del sufragio a través de los estados, y que cuando la proporción de la población minoritaria aumenta también lo hace la severidad de las leyes de privación del sufragio. ${ }^{27}$ Behrens demostró que, después de revisar otros factores relevantes, los estados con mayor población penitenciaria no blanca fueron más propensos a privar a los criminales condenados que los estados con proporciones menores de presos no blancos, y estas políticas de privación tienden a ser más restrictivas. ${ }^{28}$

Similares patrones de desigualdad en la privación del sufragio son evidentes en otros países. Por ejemplo, en Australia, los indígenas son 16 veces más propensos a ser encarcelados que los no indígenas, y la privación del sufragio tiene un efecto desproporcionado sobre ellos. ${ }^{29} \mathrm{El}$ impacto desproporcionado que la política de privación del sufragio de Canadá ha tenido en su población aborigen fue reconocida por la Corte en Sauvé v. Canada. La investigación psicológica podría examinar el impacto psicosocial que la "dilución del voto racional" tiene sobre las minorías privadas de sufragio y en los estereotipos de los grupos mayoritarios acerca de ellos.

\section{La injusticia}

En la mayoría de los países, perder el derecho a votar no es una sanción penal, sino que es una sanción administrativa basada en una legislación sin carácter penal y que se impone automáticamente. ${ }^{30}$ Se trata de una privación de un derecho que resulta como consecuencia directa de una condena penal. Como tal, se considera una "consecuencia colateral". ${ }^{31}$ Como castigo, la privación del sufragio es injusta. En la mayoría de los países no es proporcional a la severidad de la ofensa, porque es aplicada al general de los delitos, y en algunos países se sigue castigando con ella incluso después de que el delincuente ha cumplido su condena. Además, su imposición no es controlada por un juez.

${ }^{26}$ Por ejemplo, Behrens, A., Uggen, C., Manza, J., "Ballot manipulation and the 'menace of Negro domination': Racial threat and felon disenfranchisement in the United States, 1850-2002”. American Journal of Sociology, 109, 2003, pp. 559-605; Ewald, op. cit. en nota 14; Keyssar, op. cit. en nota 7; Preuhs, R. R., "State felon disenfranchisement policy". Social Science Quarterly, 82, 2001, pp. 733-748; Shapiro, A. L., "Note: Challenging criminal disenfranchisement under the Voting Rights Act: A new strategy". Yale Law Journal, 103, 1993, pp. 537-566.

${ }^{27}$ Preuhs, op. cit. en nota 26.

${ }^{28}$ Behrens, et al., op. cit. en nota 26.

29 Davidson, J., "Inside outcasts: Prisoners and the right to vote in Australia". Current Issues Brief $\mathrm{N}^{\circ}$ 12, 2003-04. Information and Research Services, Parliamentary Library, Department of Parliamentary Services.

${ }^{30}$ Por el contrario, en Alemania, la negación de los derechos de voto no es automática. Se limita a delitos graves, es impuesta por el juez en la sentencia, y procede sólo dentro de los 2 a 5 años seguidos a la liberación (Demleitner, N., "Continuing payment on one’s debt to society: The German model of felon disenfranchisement as an alternative”. Minnesota Law Review, 84, 2000, pp. 753-804.

${ }^{31}$ Olivares, K. M., Burton, V. S., Cullen, F. T., "The collateral consequences of a felony conviction: A national study of state legal codes 10 years later". Federal Probation, 60, 1996, pp. 10-17. 
La privación del sufragio también puede dar lugar a sentimientos de estar siendo tratado en forma parcial e injusta, particularmente en los Estados Unidos, donde la legislación penal y las leyes de privación del sufragio difieren entre los diversos estados. En primer lugar, hay diferencias en los códigos penales de estados (jurisdicciones) que tienen leyes de privación similares. Esto significa que dos personas que realizan el mismo comportamiento en dos estados diferentes van a ser tratados de diferente manera en relación con la privación de derecho a votar si un estado clasifica la conducta como ilegal y el otro no. En segundo lugar, existen diferencias en las leyes de privación del sufragio por crímenes entre estados que tienen similares códigos penales. Dos personas pueden ser condenadas por delitos similares en dos estados diferentes, pero una persona estará autorizada para votar y la otra no. Además, un (ex) criminal puede perder el derecho a votar si es transferido o se mueve de un Estado que permite a los criminales votar a un Estado que no lo permite (y viceversa). Por último, en algunos estados es posible competir en las elecciones, pero no está permitido votar. La investigación psicológica podría medir las percepciones de las personas acerca de la imparcialidad de la política de privación del sufragio.

\section{BENEFICIOS DE LA INTEGRACIÓN}

\section{Reinserción Social}

El artículo 10 del PIDCP establece: "1. Toda persona privada de libertad será tratada humanamente y con el respeto debido a la dignidad inherente al ser humano”. "3. El régimen penitenciario consistirá en un tratamiento cuya finalidad esencial será la reforma y la readaptación social de los penados”. Esto ha sido reconocido por los tribunales como la Corte Suprema del Canadá (2002) y el Tribunal Constitucional de Sudáfrica (1999) cuando se pronunció en contra de la privación del sufragio. Las elecciones enfatizan que todos somos miembros de una comunidad, trabajando para un bien común, y que tenemos vínculos sociales. La votación representa una forma de crear y mantener esos vínculos. Por lo tanto, psicológica y socialmente, el derecho a voto podría permitir a los presos percibirse a sí mismos como útiles, responsables, confiables y como ciudadanos respetuosos de la ley. Esto podría favorecer su rehabilitación y ayudarles a reintegrarse en la sociedad después de la liberación.

La privación del sufragio, sin embargo, sirve para aumentar la distancia social entre el delincuente y la comunidad, y reafirma sus sentimientos de alienación y aislamiento. Esto puede impedir, de su parte, la aceptación y el respeto de las normas sociales y el imperio de la ley. La privación del sufragio también etiqueta negativamente a los individuos como ciudadanos "de segunda clase". En una encuesta a 33 criminales condenados en los Estados Unidos, Uggen y Manza encontraron que la privación del sufragio fue estigmatizador y un signo de aislamiento social, incluso si las personas no habían ejercido su derecho a voto en el pasado $^{32}$. Los criminales dieron cuenta de la

32 Uggen, C., Manza, J., "Disenfranchisement and the civic reintegration of convicted felons", en C. Mele y T. Miller (Eds.), Civil penalties, social consequences. Routledge, New York, 2005. 
necesidad de sentirse como ciudadanos plenos. El estigma y la humillación de que se les niegue el derecho a votar puede ser perjudicial para la adquisición de esta imagen de sí mismo. De hecho, la privación permanente del sufragio sugiere que una persona no cambiará nunca y siempre será un desviado. ${ }^{33}$ Tal etiquetamiento puede llevar a nuevas actividades delictivas. ${ }^{34}$

Hay algunas pruebas que indican que el comportamiento electoral y el comportamiento criminal están relacionados. En un estudio longitudinal de 1.000 adultos jóvenes, Uggen y Manza encontraron que sólo alrededor del $5 \%$ de los votantes habían sido detenidos o encarcelados en comparación con los no-votantes de los cuales el 16\% había sido detenido y el $12 \%$ había sido encarcelado. ${ }^{35}$ Entre los detenidos con anterioridad, aproximadamente el $27 \%$ de los no votantes habían sido otra vez detenidos en comparación con el $12 \%$ de los votantes. Patrones similares surgen cuando se examina el crimen autorreportado de tal manera que los electores reportaron significativamente menos delitos que los no votantes. Por lo tanto, la votación parece ser parte de un "paquete de comportamiento prosocial". Investigación adicional podría iluminar los elementos de este "paquete" y estudiar cómo se relaciona con el comportamiento electoral. La investigación psicológica podría también identificar los mecanismos por los cuales la privación del sufragio afecta el autoconcepto y cómo éste media en el impacto de la política de privación del sufragio sobre la conducta delictual futura.

\section{Empoderamiento político}

Negar a los presos el derecho a votar puede tener un impacto real en la política de un país. La mayoría de los delincuentes son pobres o de clase trabajadora, y como se ha señalado, en muchos países hay un número desproporcionado de miembros de minorías étnicas representadas entre sus filas. Estos grupos son propensos a votar por liberales o demócratas en lugar de conservadores o republicanos. En los Estados Unidos, Uggen y Manza estiman que desde 1972, en promedio, 35\% de los criminales privados de sufragio habría votado en las elecciones presidenciales y el $24 \%$ habría votado en las elecciones del Senado. ${ }^{36}$ Alrededor de siete de cada diez votos emitidos por los delincuentes condenados habrían sido para el Partido Demócrata. Históricamente, por lo tanto, siete elecciones senatoriales se podrían haber volcado en favor de los demócratas si los criminales hubieran podido votar. Se ha estimado que el resultado de la elección

33 Aunque el restablecimiento de los derechos a voto puede tener el potencial de la rehabilitación penal de desetiquetación y reintegración, esto es poco probable que ocurra cuando la restauración requiere un esfuerzo y se oculta de la vista del público.

${ }^{34}$ Véase Becker, H. S., Outsiders: Studies in the sociology of deviance. Free Press of Glencoe CollierMacmillan, London, 1963.

35 Uggen, C., Manza, J., "Voting and subsequent crime and arrest: Evidence from a community sample”. Columbia Human Rights Law Review, 36, 2004, pp. 193-215.

${ }^{36}$ Uggen, C., Manza, J., "Democratic contraction? The political consequences of felon disenfranchisement”. American Sociological Review, 67, 2002, pp. 777-803. 
presidencial de los EE.UU. del año 2000, cuando G.W. Bush ganó por 537 votos, pudo haber sido determinada por la prohibición permanente sobre los derechos a sufragio de más de 400.000 ex criminales en el estado de Florida (incluso después de excluir de la prohibición a criminales). El impacto de la restitución del voto en las elecciones a nivel local o de distrito sería mayor, ya que existe una mayor concentración de delincuentes y ex delincuentes en las zonas urbanas.

Una observación similar de los efectos políticos de la privación del sufragio se ha hecho en el Reino Unido. La Prision Reform Trust ha argumentado que en las elecciones generales de 1997, la prohibición del derecho de voto puede haber afectado los resultados en ocho circunscripciones marginales que alojan un gran número de presos. ${ }^{37}$ Por ejemplo, en Dorset South, que incluye tres cárceles que acogen cerca de 1.500 presos, un candidato conservador ganó por una mayoría de sólo 77 votos. Por lo tanto, la restitución del derecho a voto a los presos y ex delincuentes ofrece amplias oportunidades para pensar contrafácticamente acerca de cómo esas políticas pueden haber alterado las democracias.

\section{Conclusiones}

Aunque los derechos de voto se han ampliado con el tiempo a muchos grupos sociales, el sufragio no es un asunto resuelto en las democracias modernas. Muchos países democráticos niegan este derecho a los presos condenados, y algunos estados de los Estados Unidos también privan permanentemente del sufragio a ex delincuentes. En general, a millones de adultos en todo el mundo se les niega el derecho a votar a pesar de que ellos viven en una sociedad democrática. La práctica de la privación del sufragio es a menudo desigual, llevando a una "dilución del voto racial", y puede ser percibida como una injusta "consecuencia colateral" de una condena. Esto limita innecesariamente el autogobierno y la democracia representativa. Restricciones sobre el derecho de voto desactivan la capacidad de una democracia para revisarse a sí misma a través de la contribución de los votantes. Presos (y ex criminales) deben tener derecho a participar en la creación de las leyes y en el gobierno del país en que viven.

Hay, internacionalmente, una creciente liberalización de las restricciones antidemocráticas sobre el derecho a voto de los presos, de manera que en las últimas elecciones canadienses y sudafricanas los presos pudieron votar. En el futuro, los presos del Reino Unido puede que también estén en condiciones de emitir su voto. El Parlamento australiano está debatiendo la cuestión de la privación del sufragio de los presos. ${ }^{38}$ La opinión pública en los Estados Unidos apoya, en general, una política menos restrictiva sobre los derechos de voto de los ex criminales. Allí, la vía judicial ha sido poco exitosa por

\footnotetext{
${ }^{37}$ También se observa que el resultado de las elecciones podrá ser modificado en las circunscripciones donde no hay prisión, pero cuando los presos designan esa circunscripción como su residencia permanente.

38 Davidson, op. cit. en nota 29.
} 
lo poco que se ha ganado en el cuestionamiento judicial de las leyes de privación del sufragio, y aunque algunos siguen ofreciendo nuevas estrategias judiciales, ${ }^{39}$ una ruta alternativa podría consistir en cambiar la legislación estatal. ${ }^{40}$ Las conclusiones de la investigación psicológica también pueden ser usadas para defender el derecho a voto de todos los delincuentes condenados. Históricamente, la democracia ha ascendido y declinado. Como Dahl escribe: "Democracia, al parecer, es un poco azarosa. Pero sus azares también dependen de lo que hacemos nosotros mismos". ${ }^{41}$ La muerte cívica de los presos es una amenaza para la democracia que debe ser cuestionada. Entre otros beneficios ya se señaló que el derecho a voto para los presos puede estimular el debate sobre la reforma penal, así como demostrar un compromiso con los derechos humanos y civiles y la reforma democrática.

\section{BIBLIOGRAFÍA}

Allard, P., Mauer, M., "Regaining the vote: An assessment of activity relating to felon disenfranchisement laws". Sentencing Project, New York, 2000.

Becker, H. S., Outsiders: Studies in the sociology of deviance. Free Press of Glencoe Collier-Macmillan, London, 1963.

Behrens, A., Uggen, C., Manza, J., "Ballot manipulation and the 'menace of Negro domination': Racial threat and felon disenfranchisement in the United States, 1850-2002". American Journal of Sociology, 109, 2003, pp. 559-605.

Bureau of Justice Statistics, Prisoners in 2003. Department of Justice, Office of Justice Programs, Washington, 2004.

Casper, J. D., American criminal justice. Prentice-Hall, Englewood Cliffs, 1972.

DaHL, R., A preface to democratic theory. University of Chicago Press, Chicago, 1956.

Dahl, R., On democracy. Yale University Press, New Haven, 1998.

Davidson, J., "Inside outcasts: Prisoners and the right to vote in Australia". Current Issues Brief $\mathrm{N}^{\circ} 12$ 2003-04. Information and Research Services, Parliamentary Library, Department of Parliamentary Services, 2004.

Demleitner, N., "Continuing payment on one's debt to society: The German model of felon disenfranchisement as an alternative". Minnesota Law Review, 84, 1956, pp. 753-804.

Ewald, A., "“Civil death": The ideological paradox of criminal disenfranchisement laws in the United States". Wisconsin Law Review, 5, 2002, pp. 1045-1138.

Fellnar, J., Mauer, M., Losing the vote. The impact of felony disenfranchisement laws in the United States. Human Rights Watch and The Sentencing Project, New York, 1998.

Gottlieb, M. J., "One person, no vote: The laws of felon disenfranchisement". Harvard Law Review, 115, 2002, pp. 1939-1963.

Harvey, A. E., "Ex-felon disenfranchisement and its influence on the black vote: The need for a second look". University of Pennsylvania Law Review, 142, 1994, pp. 1145-1189.

39 Shapiro, op. cit. en nota 26.

${ }^{40}$ Gottlieb, M. J., "One person, no vote: The laws of felon disenfranchisement". Harvard Law Review, 115, 2002, pp. 1939-1963.

${ }^{41}$ Dahl, On democracy, cit. en nota 1, p. 22. 
Itkowitz, H., Oldak, L., "Restoring the ex-offender's right to vote: Background and developments". American Criminal Law Review, 11, 1973, pp. 721-770.

Keyssar, A., The right to vote: A contested history of democracy in the United States. Basic Books, New York, 2000.

Manza, J., Brooks, C., Uggen, C., "Public attitudes toward felon disenfranchisement in the United States". Public Opinion Quarterly, 68, 2004, pp. 275-286.

Olivares, K. M., Burton, V. S., Cullen, F. T., "The collateral consequences of a felony conviction: A national study of state legal codes 10 years later”. Federal Probation, 60, 1996, pp. 10-17.

Pinaire, B., Heumann, M., Bilotta, L., "Barred from the vote: Public attitudes toward the disenfranchisement of felons". Fordham Urban Law Journal, 30, 2003, pp. 1519-1550.

PlaninC, Z., "Should imprisoned criminals have a constitutional right to vote?". Canadian Journal of Law and Society, 2, 1987, pp. 153-164.

Preuhs, R. R., "State felon disenfranchisement policy". Social Science Quarterly, 82, 2001, pp. 733-748.

Prison Reform Trust. Barred from voting, 1994. Retrieved December 16, 2004, from http:// www.prisonreformtrust.org.uk/file_25_5_2001.html

Rottinghaus, B., ManatT, C., ManatT, K., Incarceration and enfranchisement: International practices, impact, and recommendations for reform. International Foundation for Election Systems, Washington, 2003.

Shapiro, A. L., "Note: Challenging criminal disenfranchisement under the Voting Rights Act: A new strategy". Yale Law Journal, 103, 1993, pp. 537-566.

Sheppard, M. (Executive Producer). (2004, June 18). News of CBC. Toronto: Canadian Broadcasting Corporation.

The Sentencing Project. Felony disenfranchisement laws in the United States, 2005. Retrieved April 232005 from http://www.sentencingproject.org/pdfs/1046.pdf

UGGen, C., 2003. Retrieved December 13, 2004, from http://www.righttovote.org/upload/ resources/167_UFile_UggenManzaSummary.pdf

Uggen, C., ManZa, J., "Democratic contraction? The political consequences of felon disenfranchisement”. American Sociological Review, 67, 2002, pp. 777-803.

Uggen, C., Manza, J., "Disenfranchisement and the civic reintegration of convicted felons", en C. Mele T. Miller (Eds.), Civil penalties, social consequences. Routledge, New York, 2005.

UgGen, C., Manza, J., "Voting and subsequent crime and arrest: Evidence from a community sample”. Columbia Human Rights Law Review, 36, 2004, pp. 193-215.

Casos citados:

SAUVÉ V. CANADA (Chief Electoral Officer) [2002] 3 SCR 519.

HIRST V. UK ( $\mathrm{N}^{\circ}$ 2) (74025/01) [2004] ECHR 121.

RICHARDSON V. RAMÍREZ [1974] 418 US 24. 
